\title{
Criminologie
}

\section{La peur du crime, dépossession de soi}

\section{Josée Lecor}

Volume 16, numéro 1, 1983

La peur du crime

URI : https://id.erudit.org/iderudit/017174ar

DOI : https://doi.org/10.7202/017174ar

Aller au sommaire du numéro

Éditeur(s)

Les Presses de l'Université de Montréal

ISSN

0316-0041 (imprimé)

1492-1367 (numérique)

Découvrir la revue

Citer ce document

Lecor, J. (1983). La peur du crime, dépossession de soi. Criminologie, 16(1), 101-103. https://doi.org/10.7202/017174ar d'utilisation que vous pouvez consulter en ligne.

https://apropos.erudit.org/fr/usagers/politique-dutilisation/ 
La plupart des agressions sont soudaines, imprévisibles, et se déroulent très rapidement. Voilà une des raisons pour lesquelles les personnes qui les subissent ont tant de mal à en faire le récit. Au grand désespoir de la police, d'ailleurs! De plus, l'état de léthargie ou d'inconscience momentanée prive les victimes, totalement ou partiellement, de leur capacité de percevoir les événements. Voilà pourquoi l'auteure du témoignage présenté ici ne peut se prononcer définitivement sur la nature exacte du crime dont elle a été l'objet, ayant perdu conscience immédiatement après l'attaque. Voie de fait, vol qualifié, agression sexuelle? Les faits objectifs connus portent à croire qu'il s'agissait d'une agression en vue de vol. Émotion primaire, la peur défie le langage et les techniques de l'étude scientifique. Elle se prête mal aux froides descriptions et analyses. Pour la comprendre dans ses répercussions, dans ses dimensions quotidiennes, il faut écouter ceux qui la vivent. C'est ainsi que nous avons invité Josée Lecor à définir ce qu'est la peur du crime pour elle et comment elle se manifeste. Josée Lecor n'existe pas. c'est le nom qu'a emprunté l'auteur du témoignage qui préfère ne pas être identifiée car elle craint la stigmatisation et les représailles.

Le 12 février 1980, j'ai été attaquée par deux hommes en sortant du super-marché. J'étais seule. C'était en fin de journée. La surprise, les sacs que je transportais, la noirceur, m'ont paralysée et je n'ai pas pu me défendre. J'ai été frappée, malmenée, par deux individus que je ne connaissais pas, pour une raison que j'ignore. J'ai repris conscience à l'hôpital. Beaucoup de policiers sont venus, beaucoup de personnes, puis quand la nouveauté est passée, on m'a laissée seule. Après quelque temps, les policiers ont abandonné l'enquête parce qu'il n'y avait aucun espoir de retrouver ceux qui m'ont attaquée.

Pourquoi ont-ils posé ce geste? Pour quelques dollars qui restaient dans mon sac? Ils n'avaient qu'à les demander. Sous l'influence de la drogue? Pour le plaisir de faire mal ? Nous ne le saurons sans doute jamais. Pour eux, l'histoire est finie depuis plus de deux ans. Ils ont probablement oublié. Moi, je continue à la vivre et j'essaie de l'oublier. Depuis ce temps, j'essaie de réapprendre à vivre, réapprendre à

\footnotetext{
* Victime anonyme.
} 
sourire et à faíre confiance. À marcher librement dans la rue, dans les magasins. Comme avant. Je vais au super-marché, mais pas le même et pas en fin de journée. Je travaille. Je circule. Mais le fil de ma confiance est cassé. Je ne sais plus apprécier les jours nouveaux, j'ai trop peur d'eux. Je ne sais pas quelle surprise ils ont pour moi.

Vous m'avez demandé de parler de la peur. Et je ne sais pas comment dire. Sur le coup, au moment de l'attaque, la peur est animale. C'est très instinctif, émotif. Il y a beaucoup de volonté de survivre. Il y a une très grande énergie qui est libérée. Il y a aussi l'horreur, un refus ; je ne pouvais pas croire que ça m'arrivait à moi, je ne comprenais pas mais je refusais de mourir. À ce moment-là, la peur, elle est positive. Elle peut faire la différence entre la vie et la mort. Je n'étais pas encore une victime parce que, même si j'étais meurtrie et terrifiée, je n'avais pas encore le sentiment d'avoir perdu.

Plus tard, à l'hôpital, il y eut des moments où j'étais exaltée d'avoir survécu. C'était un peu comme si j'avais réussi quelque chose d'extraordinaire. J'aurais dû être morte et je vivais. Il me restait l'essentiel, la vie.

Ce qui a été beaucoup plus difficile, beaucoup plus long, ce fut de réapprendre à vivre et à faire confiance. C'est à ma vie que j'ai peur. Pas juste à ma vie qui tient aux poumons et au cœur. J'ai peur de souffrir, j'ai peur d'avoir peur, j'ai peur d'être détruite vivante. J'ai appris une vérité terrible : je suis vulnérable. Mon corps est vulnérable. Il peut souffrir, je peux souffrir, il peut se briser, me laisser n'importe quand. La mort, quand tu es pétant de vie, ça ne veut rien dire, qui y a jamais cru ? La mort, c'est la vieillesse, la maladie, au pire c'est un accident. Ça arrive aux autres, ça ne se produit pas quand tu es jeune et en santé et que tu sors du super-marché en planifiant le repas du soir. Et tout-à-coup, on y fait face, pour vrai, juste comme ça. Ce que j'ai vécu, c'est ma mort. Et maintenant, je sais et c'est une connaissance qui me hante.

J'ai appris aussi qu'on ne contrôle pas plus sa vie émotive que sa vie physique. Les deux peuvent être démolies du jour au lendemain. C'est une découverte qui enlève beaucoup de confiance en soi et aux autres. La peur du crime, ce n'est pas seulement la peur d'être attaqué, c'est aussi une méfiance générale, le sentiment de ne pas être en sécurité, que tout peut arriver. On essaie de se protéger, on se méfie, on change ses habitudes de vie, tout en sachant très bien qu'on n'est jamais à l'abri des événements. 
Le pire, c'est que toute cette souffrance ne sert à rien, ni à personne. Ma mort n'aurait eu aucun sens. Elle n'aurait été qu'un fait divers, une vulgarité, ume malpropreté. Je n'ai été qu'un jouet pour des individus qui y ont gagné quoi ? Le sentiment d'être forts et virils, des vrais hommes? N'importe qui, n'importe quand, pourvu qu'il soit un peu plus fort et qu'il ait l'avantage de la surprise peut détruire ma vie, comme ça, pour rien, sans profit pour lui-même. Pour moi, c'est ça la peur du crime ; c'est ne plus posséder ma vie, mon temps, mon espace.

À ce moment, la peur devient un sentiment négatif, destructeur. D'abord, c'est un handicap qui nous prive de faire des activités, qui nous enlève une certaine jouissance de la vie, qui nous oblige à toujours prendre des précautions. En second lieu, la peur nuit à la vie sociale parce qu'on n'ose plus parler à des inconnus, faire de nouvelles connaissances. Même les relations qu'on avait avec des amis et les membres de la famille sont diminuées, plus tendues, parce que les gens ne comprennent pas le comportement et la peur d'une personne qui a été agressée.

Vous me demandez de parler de tolérance ou de châtiments. Jusqu'ici, je me suis trop occupée de survivre pour avoir l'énergie de penser à mes agresseurs. Ils n'ont pas été arrêtés de toute façon. Le plus important aurait été de les retrouver. Il n'est pas juste de les laisser libres de détruire ma liberté et celle de tout le monde. Ce n'est pas juste de les laisser faire des victimes quand bon leur semble. Peut-être qu'ils ne comprennent même pas les conséquences de leur geste. Il faut avoir soi-même subi une agression criminelle pour en comprendre la portée. Il faudrait qu'ils subissent eux-mêmes ce qu'ils infligent à d'autres.

Je ne connais pas la solution. La seule chose importante est d'empêcher de tels individus de poser les mêmes gestes de nouveau. Mais comment? 